\title{
Use of an ADCP to Compute Suspended-Sediment Discharge in the Tidal Hudson River, New York
}

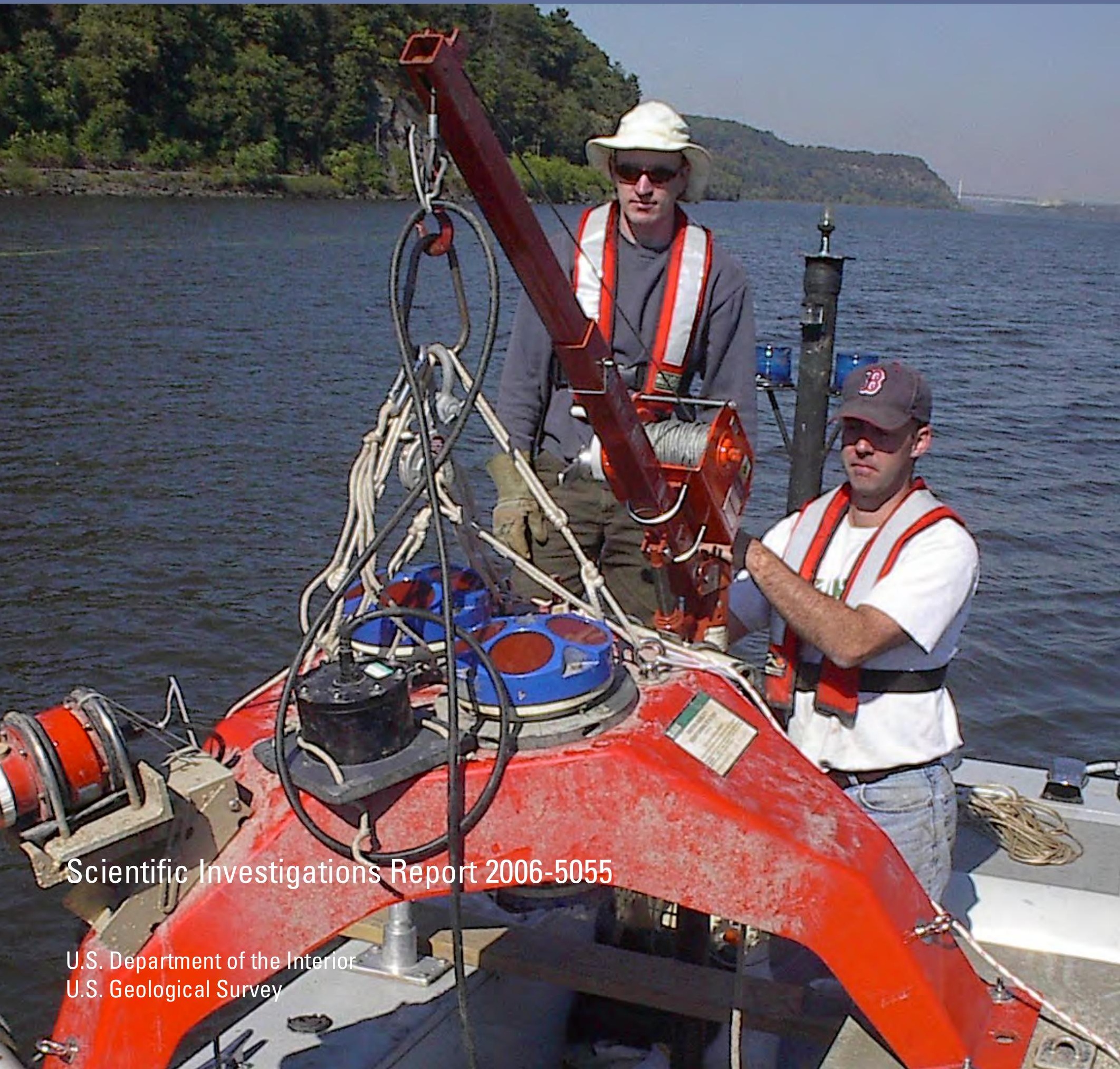


This page has been left blank intentionally. 


\section{Use of an ADCP to Compute Suspended- Sediment Discharge in the Tidal Hudson River, New York}

By Gary R. Wall, Elizabeth A. Nystrom, and Simon Litten

In cooperation with New York State Department of Environmental Conservation

Scientific Investigations Report 2006-5055 


\section{U.S. Department of the Interior DIRK KEMPTHORNE, Secretary \\ U.S. Geological Survey \\ P. Patrick Leahy, Acting Director}

U.S. Geological Survey, Reston, Virginia: 2006

Revised: 2008

For product and ordering information:

World Wide Web: http://www.usgs.gov/pubprod

Telephone: 1-888-ASK-USGS

For more information on the USGS--the Federal source for science about the Earth, its natural and living resources, natural hazards, and the environment:

World Wide Web: http://www.usgs.gov

Telephone: 1-888-ASK-USGS

Any use of trade, product, or firm names is for descriptive purposes only and does not imply endorsement by the U.S. Government.

Although this report is in the public domain, permission must be secured from the individual copyright owners to reproduce any copyrighted materials contained within this report.

Suggested citation:

Wall, G.R., Nystrom, E.A., and Litten, Simon, 2006, Use of an ADCP to compute suspended-sediment discharge in the tidal Hudson River, New York: U.S. Geological Survey Scientific Investigations Report 2006-5055, 16 p. 


\section{Contents}

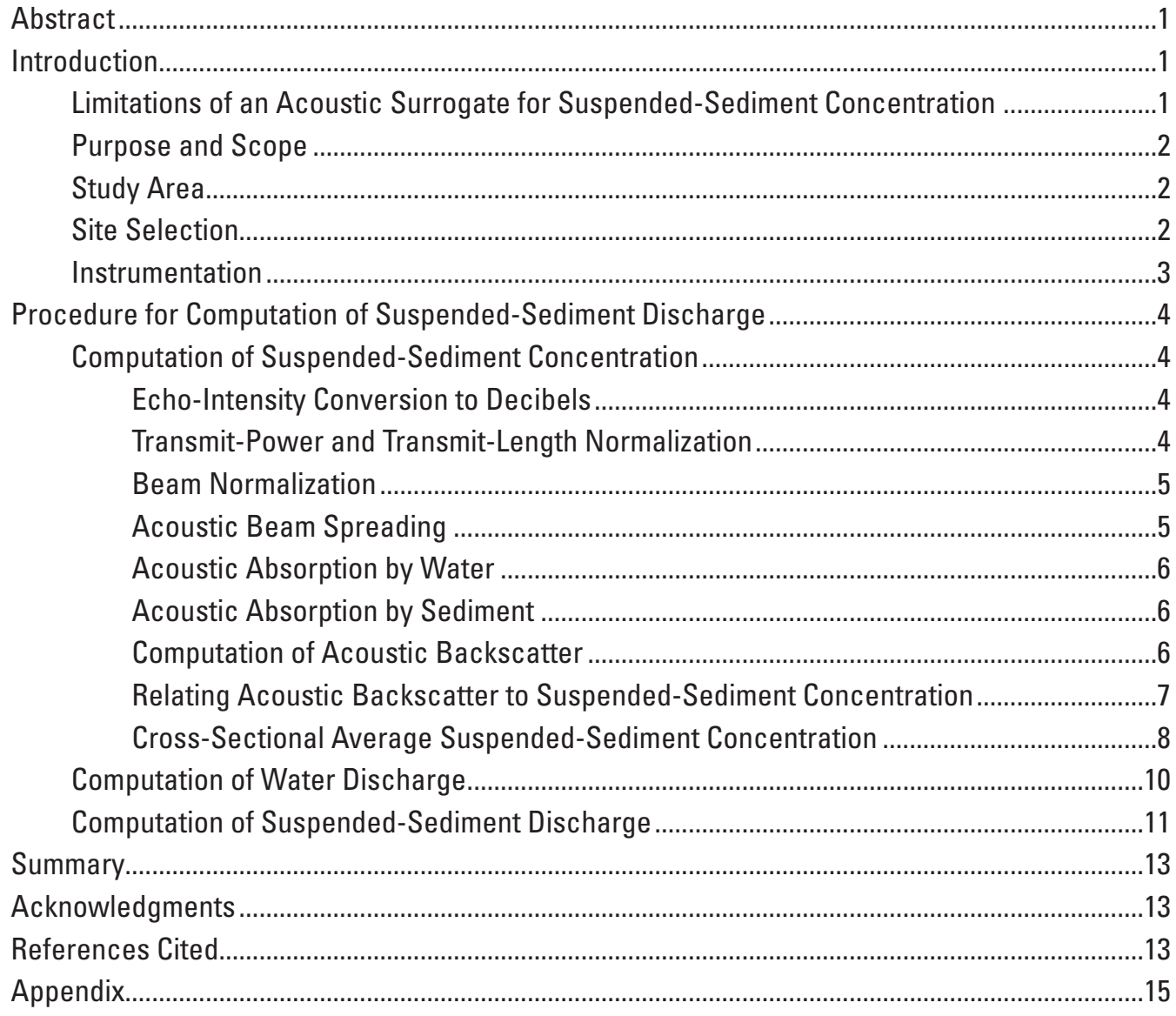

\section{Figures}

1. Map showing principal geographic features of the Hudson River Basin and location of the study site near Poughkeepsie, N.Y......................................................

2. Cross section showing river-bottom profile at study site near Poughkeepsie, N.Y.........3

3. Schematic diagram of upward-looking acoustic Doppler current profiler (ADCP) ........3

4-5. Graphs showing:

4. Relation between echo intensity recorded in bins $5,10,15,20,25$, and 30 of beams 1 and 2 of $A D C P_{1}$

5. Attenuation curves of a 614-kilohertz acoustic signal for four suspendedsediment concentrations as a function of grain size...

6. Schematic diagram showing position of (ADCP) and water sampler for ADCP calibration

7. Graph showing relation between the base-10 logarithm of suspended-sediment concentration and the predicted base-10 logarithm of suspended-sediment concentration derived from acoustic backscatter and water-temperature data measured at the same depth and time. 
8. Schematic vertical section of river showing location of zone in which acoustic Doppler current profiler (ADCP) data were obtained for suspended-sediment concentration (SSC) computation, and zones in which ADCP data were unavailable and SSC estimated.....

9-11. Graphs showing:

9. Relation between estimates of suspended-sediment concentration based on upward-looking acoustic Doppler current profiler (ADCP) measurements and those based on boat-mounted cross-sectional ADCP measurements.

10. Relation between discharge predicted by equation $14 \mathrm{a}$ and $14 \mathrm{~b}$ and that measured by boat-mounted acoustic Doppler current profiler

11. A. Daily suspended-sediment discharge computed with tidal-filtered and unfiltered data. $B$. Daily difference between filtered and unfiltered values computed in $A$. C. Percent difference between cumulative filtered and unfiltered data over time

\section{Tables}

1. Scale factors used for conversion of ADCP counts to decibels

2. Regression statistics relating echo intensity recorded in each instrument beam to those in $\mathrm{ADCP}_{1}$ Beam 1 .

3. Percent error resulting from omission of corrections and normalizations to data collected during a 208-day acoustic Doppler current profiler (ADCP) deployment in the Hudson River near Poughkeepsie, N.Y. 


\section{Conversion Factors}

\begin{tabular}{|c|c|c|}
\hline Multiply & By & To obtain \\
\hline \multicolumn{3}{|c|}{ Length } \\
\hline micron $(\mu \mathrm{m})$ & 0.00003937 & inch \\
\hline centimeter $(\mathrm{cm})$ & 0.3937 & inch \\
\hline meter $(\mathrm{m})$ & 3.281 & foot \\
\hline kilometer (km) & 0.6214 & mile \\
\hline \multicolumn{3}{|c|}{ Volume } \\
\hline liter (L) & 0.2642 & gallon \\
\hline \multicolumn{3}{|c|}{ Flow rate } \\
\hline meter per second $(\mathrm{m} / \mathrm{s})$ & 3.281 & foot per second \\
\hline cubic meters per second $\left(\mathrm{m}^{3} / \mathrm{s}\right)$ & 35.31 & cubic foot per second \\
\hline \multicolumn{3}{|c|}{ Mass } \\
\hline milligram (mg) & 0.00003527 & ounce, avoirdupois \\
\hline tons (metric) & 1000 & kilograms \\
\hline tons (metric) & 2204.6226 & pounds \\
\hline \multicolumn{3}{|c|}{ Pressure } \\
\hline pascals $(\mathrm{Pa})$ & 0.000145 & pound-force per inch \\
\hline newtons per square meter $\left(\mathrm{N} / \mathrm{m}^{2}\right)$ & 0.000145 & pound-force per inch \\
\hline $\begin{array}{l}\text { kilonewtons per square meter } \\
\qquad\left(\mathrm{KN} / \mathrm{m}^{2}\right)\end{array}$ & 0.009869 & atmospheres \\
\hline bars & 0.9869 & atmospheres \\
\hline \multicolumn{3}{|c|}{ Equivalent concentration terms } \\
\hline grams per liter (g/) & 1 & parts per thousand \\
\hline milligrams per liter (mg/L) & 1 & parts per million \\
\hline
\end{tabular}

Temperature in degrees Celsius $\left({ }^{\circ} \mathrm{C}\right)$ may be converted to degrees Fahrenheit $\left({ }^{\circ} \mathrm{F}\right)$ and degrees Kelvin $\left({ }^{\circ} \mathrm{K}\right)$ as follows:

$$
{ }^{\circ} \mathrm{F}=\left(1.8 x^{\circ} \mathrm{C}\right)+32 \quad{ }^{\circ} \mathrm{K}={ }^{\circ} \mathrm{C}+273.15
$$


This page has been left blank intentionally. 


\title{
Use of an ADCP to Compute Suspended-Sediment Discharge in the Tidal Hudson River, New York
}

\author{
By Gary R. Wall', Elizabeth A. Nystrom', and Simon Litten²
}

\begin{abstract}
Acoustic Doppler current profilers (ADCPs) can provide data needed for computation of suspended-sediment discharge in complex river systems, such as tidal rivers, in which conventional methods of collecting time-series data on suspended-sediment concentration (SSC) and water discharge are not feasible. Although ADCPs are not designed to measure SSC, ADCP data can be used as a surrogate under certain environmental conditions. However, the software for such computation is limited, and considerable post-processing is needed to correct and normalize ADCP data for this use. This report documents the sampling design and computational procedure used to calibrate ADCP measures of echo intensity to SSC and water velocity to discharge in the computation of suspended-sediment discharge at the study site on the Hudson River near Poughkeepsie, New York. The methods and procedures described may prove useful to others doing similar work in different locations; however, they are specific to this study site and may have limited applicability elsewhere.
\end{abstract}

\section{Introduction}

Computation of instantaneous suspended-sediment discharge, or the mass of suspended sediment moving past a given river cross section per unit time, requires multiplying the average suspended-sediment concentration (SSC) in the river cross section by the volume of water passing that cross section per unit time (water discharge). Computation of the suspended-sediment discharge over time requires collection of SSC and discharge data at a frequency sufficient to permit a reasonable interpolation between data points (Potterfield, 1972). Environments in which SSC and discharge change little over time require fewer data than those environments in which

${ }^{1}$ U.S. Geological Survey

${ }^{2}$ New York State Department of Environmental Conservation flow conditions change rapidly, such as in a tidal river. Rapidly changing conditions require a surrogate for SSC because the large number of samples required becomes difficult and costly to obtain. River stage can be used as a surrogate for discharge in rivers where the water level is controlled by a fixed physical feature such as a riffle or dam, but stage cannot be used in tidal rivers, where the control (sea level) is variable. Acoustic Doppler current profilers (ADCPs) can be used, however, to provide surrogates for discharge (Morlock and others, 2002) and, in some settings, SSC (Gartner and others, 2003) through measures of velocity and echo intensity (EI), respectively.

\section{Limitations of an Acoustic Surrogate for Suspended-Sediment Concentration}

Currently available ADCPs are single-frequency instruments and as such are unable to resolve whether changes in EI are associated with changes in sediment concentration or changes in particle-size distribution (Reichel and Nachtnebel, 1994). Interpretation of EI data therefore requires additional measures or assumptions to resolve the cause of these changes. This limitation makes any relation between SSC and EI site-specific. A second limitation of an acoustic surrogate is the relation between particle circumference and ADCP frequency (Reichel and Nachtnebel, 1994). Error in SSC estimates has been found to increase as the ratio of particle circumference to acoustic wavelength approaches 1 (Gartner, 2004). A third limitation is that ADCPs are designed to detect acoustic frequency changes in current profiles and are less accurate in measuring the amplitude changes associated with EI measurements (Schaafsma and others, 1997). Other factors that complicate the development of a relation between EI and SSC include the impossibility of collecting acoustic data and a water sample for SSC analysis from the same location at the same time, the need for data corrections to account for the loss of acoustic energy with distance from the ADCP, and normalizations for fixed and dynamic differences between instruments and instrument components over time. 


\section{Purpose and Scope}

In 2001, The U.S. Geological Survey (USGS), in cooperation with the New York State Department of Environmental Conservation, designed a sampling protocol and computational procedure to process ADCP data to determine suspended-sediment discharge. This report documents the sampling design and computational procedure used to derive net suspended-sediment discharge from measures of acoustic backscatter and water velocity at a site in the freshwater-tidal Hudson River near Poughkeepsie, N.Y. for the assessment of suspended-sediment discharge toward New York Harbor. Because of the many complications of applying this emerging SSC surrogate technology to a variety of river systems nationwide, the USGS does not currently have a standard operating procedure (SOP) for the use of ADCPs for estimation of suspended-sediment discharge; this report is

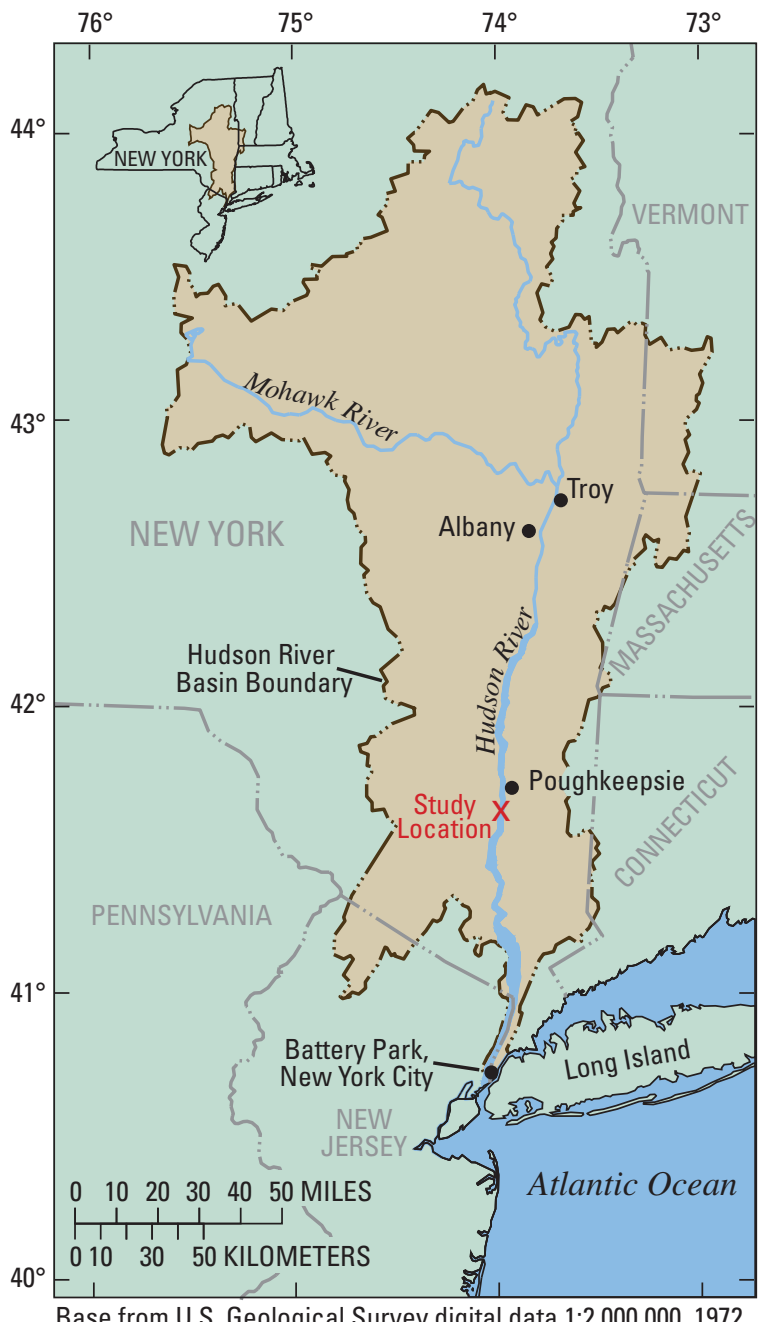

Figure 1. Principal geographic features of the Hudson River Basin and location of the study site near Poughkeepsie, N.Y. not intended to be that SOP. This report may prove useful to others wanting to do similar work at other sites; however, the procedure and assumptions described herein are specific to the study site and may have limited applicability elsewhere.

\section{Study Area}

The tidal Hudson River extends $247 \mathrm{~km}$ north of its mouth at New York Harbor to the head-of-tide at the Federal Lock and Dam in Troy, N.Y. (fig. 1). It is the largest source of terrestrial sediment entering New York Harbor, which needs to be dredged regularly to maintain navigation. River stage is affected by a semidiurnal tide; the mean tidal range at the study site is $0.95 \mathrm{~m}$ (Center for Operational Oceanographic Products and Services, 2005), and the maximum water depth is about $18 \mathrm{~m}$. The river channel at the site is nearly straight, with steep banks and a nearly flat bottom over its approximately $800 \mathrm{~m}$ width (fig. 2). Several near-surface grab samples of river-bottom sediment indicate that the bottom consists mainly of cohesive estuarine clay with isolated pockets of fluid-rich clay and mud. Recovery of several pieces of coal slag in bottom samples throughout the site cross section, presumably dumped overboard from steamboats that were used on the river for 150 years until the mid-1950s, indicate that the reach is nondepositional at present. The site is typically freshwater throughout the year, although brackish water can advance as far as $19.3 \mathrm{~km}$ inland of the site (deVries and Weiss, 2001) during periods of extended drought and low inflow from tributaries.

\section{Site Selection}

The study site within the tidal Hudson River was selected for three reasons. First, except under extremely dry conditions in the watershed, it is the furthest downriver location that remains year-round in freshwater, which is desirable because salinity changes increase the potential for particle flocculation and thus a shift in particle-size distribution. Second, a series of 74 cross-sectional measurements of discharge and acoustic backscatter made with a boat-mounted ADCP over a 25-hour period in June 2001 qualitatively suggested that SSC was reasonably well distributed in this cross section throughout the tidal cycle. Third, the presence of a USGS tide-monitoring station (no. 01372058) on the east side of the river and a dock suitable for installing equipment on the west side facilitated data collection and transfer. The location of the bottom-mounted ADCP within the cross section was selected through an analysis of the June 2001 cross-section data from several test sites. The average velocity of several ensembles at and adjacent to each test site was plotted in relation to the respective discharge for each of the 74 cross-section measurements. The final site selection was where the relation between velocity and discharge was strongest. 


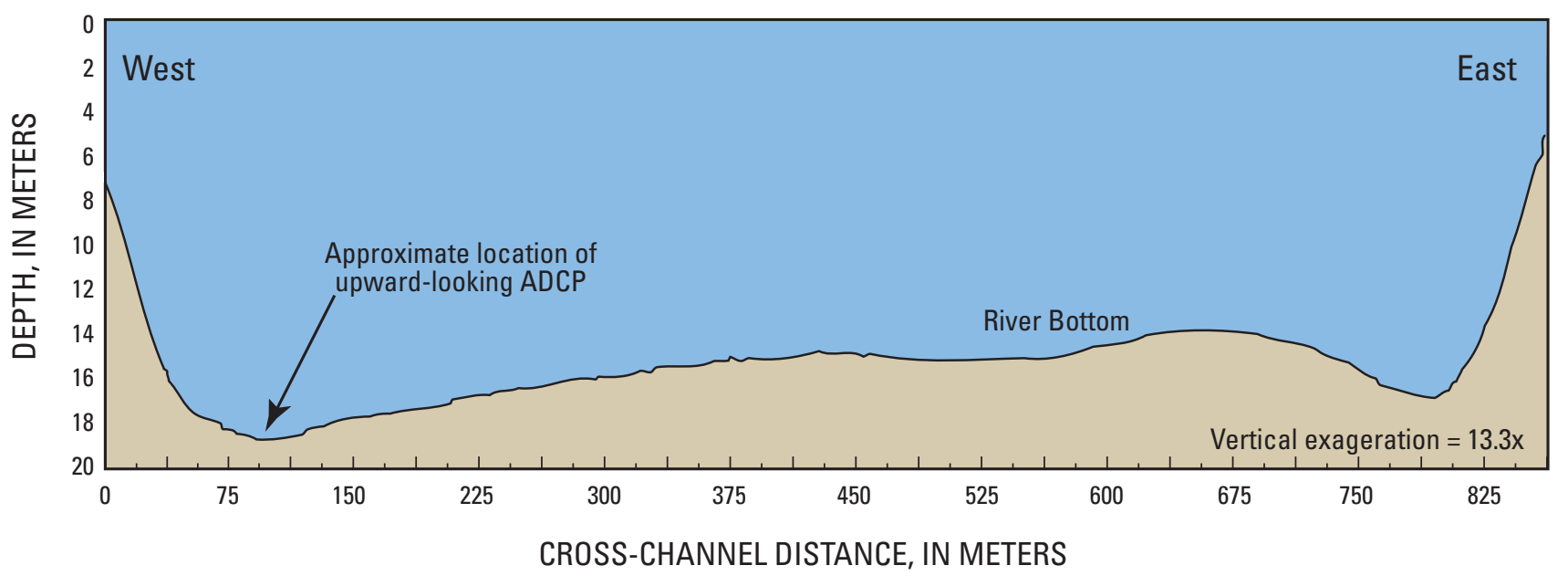

Figure 2. River-bottom profile at study site near Poughkeepsie, N.Y. (Location is shown in figure1.)

\section{Instrumentation}

ADCPs measure water velocity by transmitting an acoustic pulse through the water and recording the frequency and amplitude of echos returning from particles that are suspended in the water that are assumed to be moving at the same velocity as the water (RD Instruments, 1996). Movement of these particles toward or further away from an ADCP transducer causes a Doppler (frequency) shift in the return echo that the ADCP uses to compute the particle velocity. The amplitude of the return signal is recorded as EI. The ADCP records velocity and EI data from a series of segments or "bins" (fig. 3) that form each acoustic "beam" generated by the transducers. The ADCP uses the Doppler shift recorded in each bin and beam to resolve the velocity vector of the particles. The EI, or strength of the return echo, in certain environments (Gartner and Cheng, 2001) is proportional to SSC. The collection of sufficient surrogate data for interpretation is limited only by ADCP battery power and internal memory.

Two 614-kHz RD Instruments Workhorse Sentinel ADCPs were used, each with four transducers at a 20-degree angle to the instrument face. One ADCP was mounted to a stationary tripod on the river bottom in an upward-looking orientation about $65 \mathrm{~cm}$ above the bottom; the other was boat-mounted to measure discharge and develop a correlation between EI and SSC. Periodically the upward-looking ADCP was recovered for servicing and replaced with the other ADCP thus creating a rotation of the two instruments. Individual ADCP deployments ranged from 1 week to 7 months.
The upward-looking ADCP was set to transmit 100 acoustic pulses or "pings" every 15 minutes. The 100 pings were transmitted and echoes received by the ADCP in a span of about 20 seconds. Data from each bin in each beam were averaged into a single measurement. The size of the bins was set to 0.5 meters, which resulted in 31 to 34 bins containing valid data in each beam. The exact number of bins used was computed from the depth of water above the ADCP at the time of each measurement and the cosine of the beam angle; this computation avoided the incorporation of bins with interference from acoustic reflections off the water surface (Simpson and Oltman, 1993).

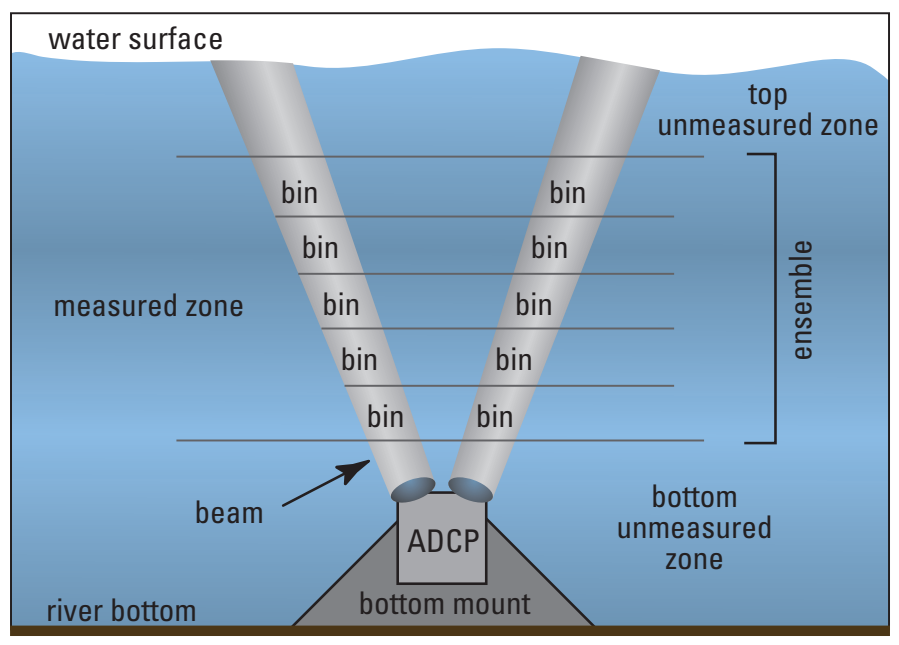

Figure 3. Schematic diagram of upward-looking acoustic Doppler current profiler (ADCP). 


\section{Procedure for Computation of Suspended-Sediment Discharge}

The following sections detail the steps used to (1) convert measures of EI to SSC and then adjust the derived SSC values to conditions in the full-river cross section; (2) relate measures of water velocity, wind stress, and river stage to water discharge; and (3) compute suspended-sediment discharge.

\section{Computation of Suspended-Sediment Concentration}

Conversion of EI data recorded by the ADCP to SSC requires corrections for (1) temporal changes in transmit power, transmit length, and the size of particles in the water; (2) spatial changes in the spreading of acoustic energy away from the transducer and the behavior of acoustic energy close to the transducer; (3) temporal and spatial changes in the sound absorption by water and suspended particles; and (4) variability between transducers. EI after normalization and (or) correction for all of the above factors, except temporal changes in particle size, is known as Acoustic Backscatter (ABS). A constant particle-size distribution over the range of observed flow conditions indicates that changes in ABS can be attributed to changes in SSC. This relation is based on the sonar equation for sound scattering (Gartner, 2004) and takes the general form:

$$
S S C=10^{(A \times A B S+B)}
$$

where $A$ and $B$ are the empirically derived slope and intercept, respectively, of the regression of SSC against ABS. The following sections outline the steps used to convert EI to SSC.

\section{Echo-Intensity Conversion to Decibels}

EI is recorded by the ADCP in counts. Counts are extracted from the ADCP data and multiplied by an instrument-specific and beam-specific scale factor (RD Instruments, oral commun., 2005) to produce EI in units of decibels (dB) (table 1). These scale factors are available from RD Instruments by request.

\section{Transmit-Power and Transmit-Length Normalization}

Transmit Power $(T P)$, which is directly proportional to EI, is a measure of the acoustic energy transmitted by the instrument into the water column. TP can vary among instruments and through time. The measurements in this study were obtained from widely differing power-supply voltages because the upward-looking measurements were powered by an internal battery whereas boat-mounted measurements were made by direct connection of inverted $\mathrm{AC}$ power. This difference caused TP to vary by a factor of 2.4 to 3.8 between upward-looking measurements (about 60-98 watts) and calibration measurements (about 25 watts). Additionally, the voltage of the upward-looking ADCP power-supply battery declined during individual deployments and resulted in a drop of as much as 25 watts (26 percent) in TP over an individual deployment.

$T P$ in watts was calculated using equation 2 from values of Transmit Current (TC) and Transmit Voltage (TV) recorded in counts, and extracted from the ADCP data (RD Instruments, oral commun., 2004):

$$
T P=(T C \times 0.011451) \times(T V \times 0.380667)
$$

All EI values were multiplied by a normalization factor (TPn) to adjust EI to a transmit power of 25 watts, the approximate value recorded during boat-mounted measurements, as expressed in equation 3 :

$$
T P n=\frac{25}{T P}
$$

Transmit Length $(T L)$ in counts is directly proportional to the length of the acoustic pulse and EI and was extracted from the ADCP data. Variability in $T L$ over a deployment was generally less than 3 counts (about 4 percent) and EI values were multiplied by a normalization factor $(T L n)$ to adjust EI to a $T L$ of 47 counts, the approximate value observed for most ensembles, as defined in equation 4 :

$$
T L n=\frac{47}{T L}
$$

Table 1. Scale factors used for conversion of acoustic Doppler current profiler (ADCP) counts to decibels.

\begin{tabular}{ccc}
\hline Instrument & Beam & Scale factor \\
\hline $\mathrm{ADCP}_{1}$ & 1 & 0.435374 \\
& 2 & .445808 \\
& 3 & .434811 \\
$\mathrm{ADCP}_{2}$ & 4 & .452868 \\
& 1 & .413125 \\
& 2 & .461776 \\
& 3 & .454131 \\
& 4 & .413284 \\
\hline
\end{tabular}




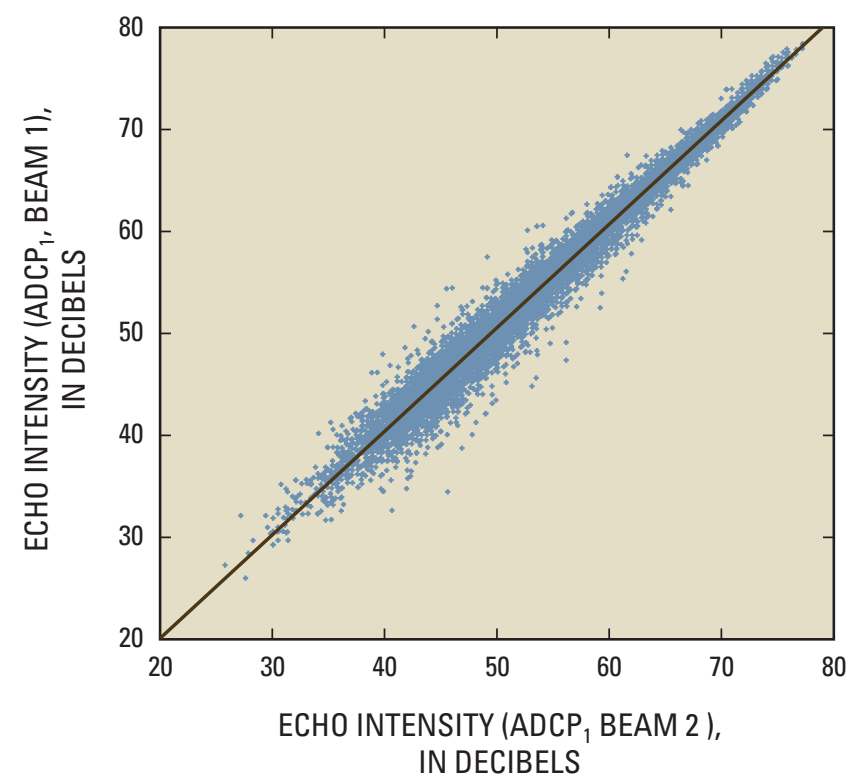

Figure 4. Relation between echo intensity recorded in bins 5 , $10,15,20,25$, and 30 of beams 1 and 2 of $A D C P_{1}$.

Table 2. Regression statistics relating echo intensity recorded in each instrument beam to those in $A_{D C P}$ beam 1 .

$\left[\mathrm{R}^{2}\right.$, coefficient of determination]

\begin{tabular}{lclll}
\hline Instrument & Beam & Slope & Intercept & $\mathbf{R}^{2}$ \\
\hline $\mathrm{ADCP}_{1}$ & 1 & 1 & 0 & 1 \\
& 2 & 1.0154 & -0.2316 & 0.98 \\
& 3 & 0.9580 & 1.2214 & 0.98 \\
& 4 & 0.9730 & -0.0578 & 0.97 \\
$\mathrm{ADCP}_{2}$ & 1 & 0.9748 & 1.1036 & 0.98 \\
& 2 & 0.9783 & -1.1721 & 0.98 \\
& 3 & 0.9697 & 0.1623 & 0.98 \\
& 4 & 0.9891 & 0.2980 & 0.98 \\
\hline
\end{tabular}

\section{Beam Normalization}

ADCP beams are not factory calibrated to produce identical values of EI for a given ensonified volume (RD Instruments, oral commun., 2004). Adjusting for this variability entailed using data gathered from a side-by-side deployment of both ADCPs over 4 weeks in October and November 2003 to normalize the beams on the two ADCPs to beam 1 on the first $\mathrm{ADCP}\left(\mathrm{ADCP}_{1}\right) . \mathrm{ADCP}_{1}$ was set to collect a 100-ping ensemble every 15 minutes and the second ADCP $\left(\mathrm{ADCP}_{2}\right)$ collected 100-ping ensembles 1 minute before and 1 minute after each $\mathrm{ADCP}_{1}$ ensemble. Each measurement took about 20 seconds to complete and allowed 40 seconds for the dissipation of any acoustic ringing from the previous measurements. The EI data from each $\mathrm{ADCP}_{2}$ bin, collected immediately before the $\mathrm{ADCP}_{1}$ measurement, were paired with data collected from the same bins immediately after the $\mathrm{ADCP}_{1}$ measurement. These data pairs were first normalized to a 25-watt transmit power and a 47-count transmit length, then averaged to produce 1 value $\left(\overline{E I_{d b}}\right)$ for comparison with the EI value recorded by $\mathrm{ADCP}_{1}$, which the data pairs bracketed. That computation is illustrated by the following equations:

$$
\overline{E I_{d b}}=10 \times \log _{10}\left[\frac{E I_{i j}+E I_{i^{\prime} j^{\prime}}}{2}\right]
$$

where

$E I_{i j}$ is the power-normalized echo intensity in beam $i$ and bin $j$ for the $\mathrm{ADCP}_{2}$ measurement immediately before the $\mathrm{ADCP}_{1}$ measurement:

$$
E I_{i j}=10^{\frac{E I_{d B}}{10}} \times T P n \times T L n
$$

and

$$
\begin{aligned}
& E I_{i^{\prime} j^{\prime}} \text { is the power-normalized echo } \\
& \text { intensity in beam } i \text { and bin } j \text { for the } \mathrm{ADCP}_{2} \\
& \text { measurement immediately after the } \mathrm{ADCP}_{1} \\
& \text { measurement: }
\end{aligned}
$$

$$
E I_{i^{\prime} j^{\prime}}=10^{\frac{E I_{d B}^{\prime}}{10}} \times T P n \times T L n
$$

Seven regression equations were generated to relate the EI data from bins in beam 1 of $\mathrm{ADCP}_{1}$ to data from the same bins in the seven other beams of $\mathrm{ADCP}_{1}$ and $\mathrm{ADCP}_{2}$. One of the regression data sets typical of all seven equations is depicted in figure 4; the slope, intercept, and coefficient of determination $\left(\mathrm{R}^{2}\right)$ are given in table 2 . To simplify data management, only data from bins $5,10,15,20,25$, and 30 were used to develop the equations. The limit of usable data was generally found in bins 31-34.

\section{Acoustic Beam Spreading}

The EI received by the ADCP is proportional to the range of the echo source particle from the ADCP. The two-way transmission loss due to beam spreading $(B S)$ is:

$$
B S=20 \times \log _{10}(R \times \psi)
$$

where

$R$ is the slant distance to the source of the return echo, in meters, defined by Deines (1999) as:

$$
R=r+\frac{D}{4}
$$

where

$$
\begin{aligned}
& r \text { is the slant distance from the transducer } \\
& \text { face to the center of a bin in meters, } \\
& D \text { is the bin size, in meters, }
\end{aligned}
$$

and

$\psi$ is a transducer near-field correction (Downing and others, 1995) that accounts for the nonspherical spreading of acoustic energy close to the transducer, defined as: 


$$
y=\frac{1+1.35 z+(2.5 z)^{3.2}}{1.35 z+(2.5 z)^{3.2}}
$$

where

$$
z=\frac{R l}{\mathrm{p} a_{t}^{2}}
$$

$a_{t}$ is the transducer radius, in meters; and

I is the acoustic wavelength, in meters.

\section{Acoustic Absorption by Water}

EI is also dependent on absorption of acoustic energy by the water (WA) according to the following equation (RD Instruments, 1996):

$$
W A=2 \mathrm{a} R
$$

where

$\alpha$, is defined by Shulkin and Marsh (1962), in nepers per meter, as:

$$
\begin{gathered}
\mathrm{a}=\left(\frac{S A f_{T} f^{2}}{f_{T^{2}}+f^{2}}+\frac{3.38 \times 10^{-6} f^{2}}{\left.21.9 \times 10^{6-[1520} / T+273\right]}\right)\left(1-6.54 \times 10^{-4} P\right) \\
\text { where } \\
\text { and } S \quad \text { is salinity, in parts per thousand; } \\
\quad P \quad \text { is water pressure, in atmospheres. }
\end{gathered}
$$

The pressure term is insignificant at $20 \mathrm{~m}$ depth, and the salinity term drops out of the equation in freshwater, reducing the equation to:

$$
a=8.687 \times \frac{3.38 \times 10^{-6} f^{2}}{21.9 \times 10^{6[-[1520 / T+273]}}
$$

where

$f$ is the acoustic frequency, in kilocycles per second;

$T$ is the water temperature, in degrees $\mathrm{C}$;

and

8.687 is the conversion factor from nepers to decibels.

\section{Acoustic Absorption by Sediment}

Attenuation of an acoustic signal by suspended sediment can be divided into viscous, scattering, and diffraction energyloss components (Flammer, 1962). The diffraction component is not a significant source of attenuation at the study site given the instrument frequency and range of observed particle sizes. The combination of viscous and scattering energy-loss components for a $614-\mathrm{kHz}$ acoustic signal at four suspendedsediment concentrations is plotted as a function of grain size in figure 5, which is based on a two-way attenuation equation by Urick (1948). The curves are based on the assumptions of spherical, rigid, and uniform-sized particles with a specific gravity of 2.65. Lower specific gravity values would shift the curves downward with respect to the attenuation coefficient. The viscous component dominates the curves at particle sizes smaller than 200 microns and the scattering component dominates losses at sizes larger than 200 microns. SSC at the study site rarely exceeded $100 \mathrm{mg} / \mathrm{L}$ and silt and clay size particles on average represented 96 percent of the material in suspension; therefore, any attenuation due to suspended sediment was from the viscous component. The lack of information on particle size less than 62 microns, and the probability that the worst-case scenario would produce a signal loss of only a few decibels over the full depth of water, led to the assumption that sound absorption by particles was negligible, and no correction was applied to account for this signal loss. The use of a high frequency ADCP at this site could possibly invalidate this assumption, in that high frequencies would cause an upward shift of the attenuation curves in figure 5.

\section{Computation of Acoustic Backscatter}

Acoustic backscatter in a given bin $\left(A B S_{b i n}\right)$, in decibels, is calculated by combining equations 6 and 7 , which describe attenuation losses, with equations 3 (transmit-power normalization), and 4 (transmit-length normalization) and the beam-normalized factors in table 2, as follows:

$$
A B S_{b i n}=10 \times \log _{10}\left[10^{\frac{\left(E I_{d B} \times A+B\right)}{10}} \times T P n \times T L n\right]+B S+W A
$$

where

$A$ and $B$ are the slope and intercept, respectively, of the empirically derived beamnormalization factors.

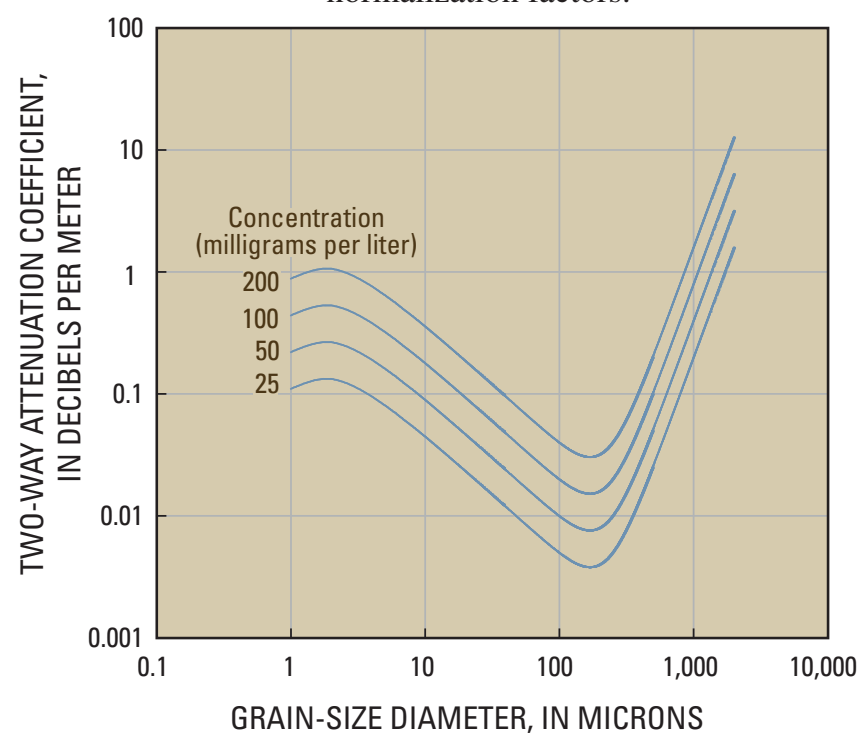

Figure 5. Attenuation curves of a 614-kilohertz acoustic signal for four suspended-sediment concentrations as a function of grain size. 
The average ABS for the same bin in each beam is defined as:

$\overline{A B S}_{b i n}=10 \times \log _{10}\left[\frac{\sum_{i=1}^{4}\left[10^{\frac{\left(E I_{d B} \times A+B\right)_{i}}{10}}\right]}{4} \times T P n \times T L n\right]+B S+W A$

where

$$
i \text { is the beam number. }
$$

ABS values, and by extension SSC values, in the bin closest to the upward-looking ADCP (bin 1) were consistently low relative to bin 2. The resulting ABS depth-profile was inconsistent with independent observations of sediment concentration and optical backscatter in the depth profile. This inconsistency was assumed to result from near-instrument phenomena not adequately accounted for in equation 9 .
As a result, ABS values in bin 1 were derived by linear extrapolation of ABS values in bins 2 and 3 .

\section{Relating Acoustic Backscatter to Suspended- Sediment Concentration}

Water samples for SSC analysis and development of a relation between ABS and SSC were collected at known depths with a $\mathrm{P}-61$ point-integrating isokinetic sampler suspended from the side of a boat. A downward-looking ADCP was mounted and run on the opposite side of the boat (fig. 6) while the sample bottle filled (about 60 seconds). EI data collected from the bin in each of the four transducer beams closest to the depth of the $\mathrm{P}-61$ sampler were averaged according to equation 9 .

River-water samples were collected at various times during the tidal cycle during several "calibration trips" when boating was possible between March and November. Typically, 3 to 6 samples at different depths were collected on

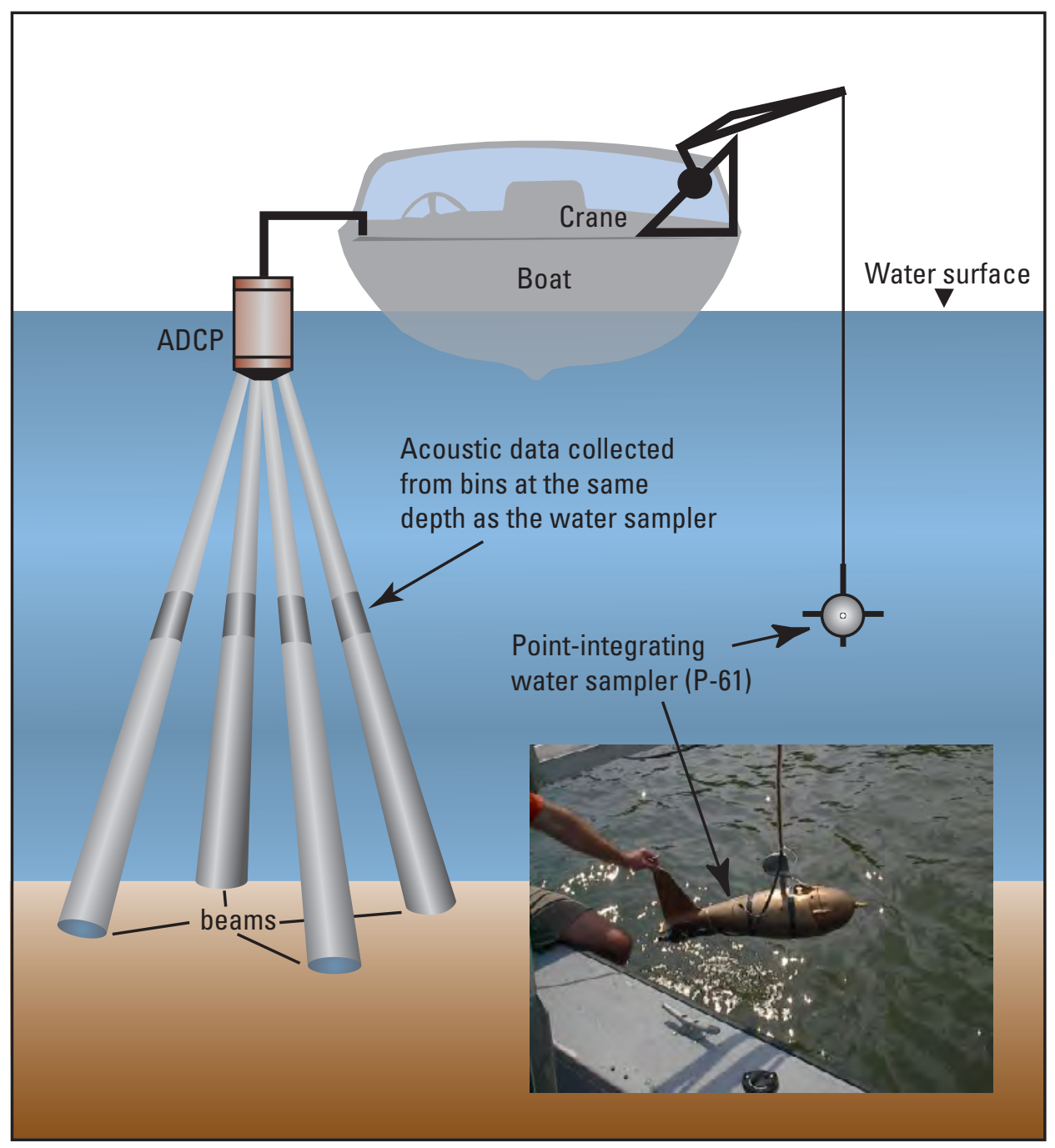

Figure 6. Schematic diagram showing position of acoustic Doppler current profiler (ADCP) and water sampler for ADCP calibration. 


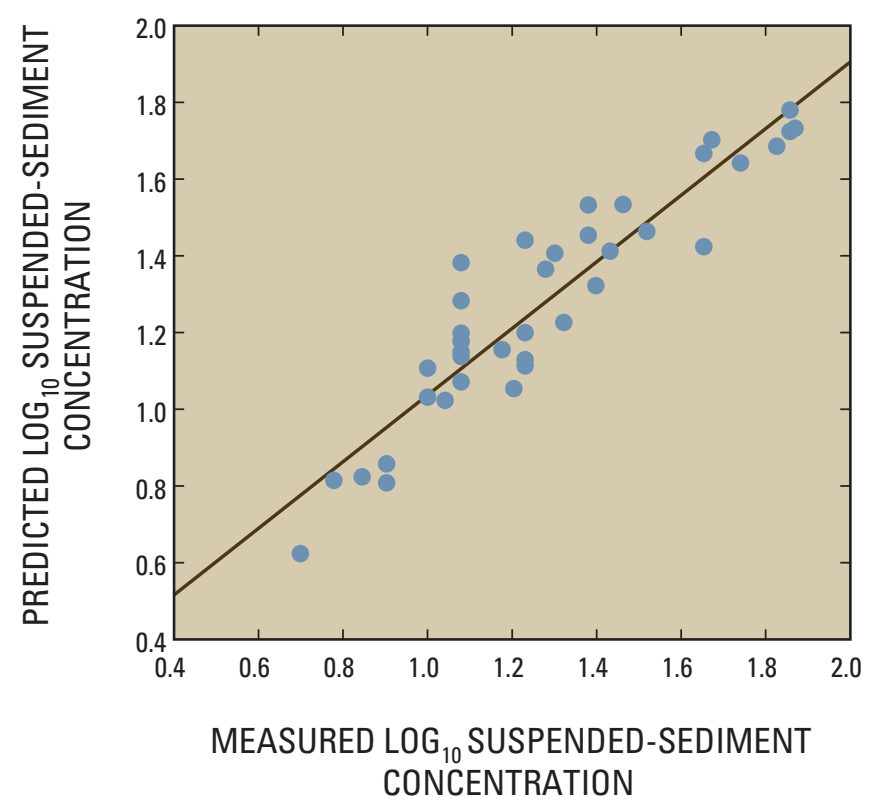

Figure 7. Relation between the base10-logarithm of suspendedsediment concentration and the predicted base10-logarithm of suspended-sediment concentration derived from acoustic backscatter and water-temperature data measured at the same depth and time.

these trips. Data from no more than 3 samples per trip were selected at random to avoid biasing the ABS to SSC relation toward any individual trip. The mean percentage of clay- and silt-size material (less than $62 \mu \mathrm{m}$ ) in these samples was 96 percent with a standard deviation of 2.9 percent; this suggests that changes in ABS are attributable mainly to changes in SSC rather than to changes in particle-size distribution.

The relation between the base-10 logarithm of measured and predicted SSC is depicted in figure 7. Predicted SSC $\left(S S C_{b i n}\right)$ is derived from a combination of two explanatory variables, $\overline{A B S}_{b i n}$ and water temperature $(W T)$ in degrees Celsius. Water temperature was found significant at the $p<0.001$ level and therefore included in the multiple regression equation. The $\mathrm{R}^{2}$ between these variables is 0.86 , and the standard deviation of the residuals (measured SSC minus retransformed-fit SSC) is $7.9 \mathrm{mg} / \mathrm{L}$. SSC, in milligrams per liter for an individual bin after retransformation, is expressed in equation 10. The average of the retransformed regression residuals (1.033), known as the Duan smearing estimator (Helsel and Hirsch, 1992), is applied to the equation to account for bias (geometric as opposed to arithmetic means) introduced by the retransformation of SSC from logarithmic to arithmetic space:

$$
S S C_{\text {bin }}=10^{\overline{A B S}_{\text {bin }} \times 0.034-W T \times 0.019-1.018} \times 1.033
$$

\section{Cross-Sectional Average Suspended-Sediment Concentration}

The ADCP-derived average SSC in the measured part of the water column (fig. 3) above the upward-looking ADCP was compared with cross-sectional measurements of SSC to produce a cross-section correction factor. The average SSC measured above the upward-looking $\operatorname{ADCP}\left(S S C_{\text {Pavg }}\right)$ was computed as:

$$
S S C_{\text {Pavg }}=\frac{\sum_{\text {bin }=1}^{n}\left(S S C_{b i n} \times\left|V p_{b i n}\right|\right)}{\sum_{\text {bin }=1}^{n}\left|V p_{b i n}\right|}
$$

where

$S S C_{b i n}$ is the SSC in an individual bin defined by equation 10 ,

and

$V p$ is the projected downstream water velocity,

$n$ is the bin farthest from the ADCP.

The large cross-sectional area of the Hudson River at the site, and constantly changing flow conditions make conventional methods of sample collection in the full cross section, such as the equal-width or equal-discharge methods (U.S. Geological Survey, 1999) infeasible for accurate measurement of the average cross-sectional concentration $\left(S S C_{\text {Xavg }}\right.$ ) for a given point in time. Boat-mounted crosssectional ADCP measurements, however, provided sufficient data from which to calculate this value while minimizing time averaging of individual measurements. The width of a given bin in an acoustic beam is dependent on the speed of the boat; therefore, cross-sectional averaging of computed SSC values was weighted by the discharge instead of velocity in each bin or unmeasured zone (fig. 8) and calculated as:

$$
\begin{aligned}
& S S C_{\text {Xavg }}=\left[\sum_{e=1}^{z}\left(\left(S S C_{\text {top }} \times\left|Q_{\text {top }}\right|\right)_{e}+\left(S S C_{\text {bot }} \times\left|Q_{\text {bot }}\right|\right)_{e}\right)+(12)\right. \\
& \left.\sum_{\text {bin }=1}^{n}\left(S S C_{\text {bin }} \times\left|Q_{\text {bin }}\right|\right)+\left(S S C_{l} \times\left|Q_{l}\right|\right)+\left(S S C_{r} \times\left|Q_{r}\right|\right)\right] \times\left|Q_{\text {Total }}\right|^{-1}
\end{aligned}
$$

where

$Q_{b i n}$ is discharge in an individual bin,

$n$ is the last measured bin in the cross section,

$\mathrm{Z}$ is the last measured ensemble in the cross section

and

$Q_{\text {Total }}$ is the cross-section discharge.

Estimates of SSC in the unmeasured zones near the river bottom $\left(S S C_{b o t}\right)$ and water surface $\left(S S C_{t o p}\right)$ of each ensemble (e) were made by fitting an ordinary least-squares line through the $S S C_{b i n}$ data from each ensemble and extrapolating to the center of the top and bottom of the respective unmeasured zones. Concentrations in these unmeasured zones were then 


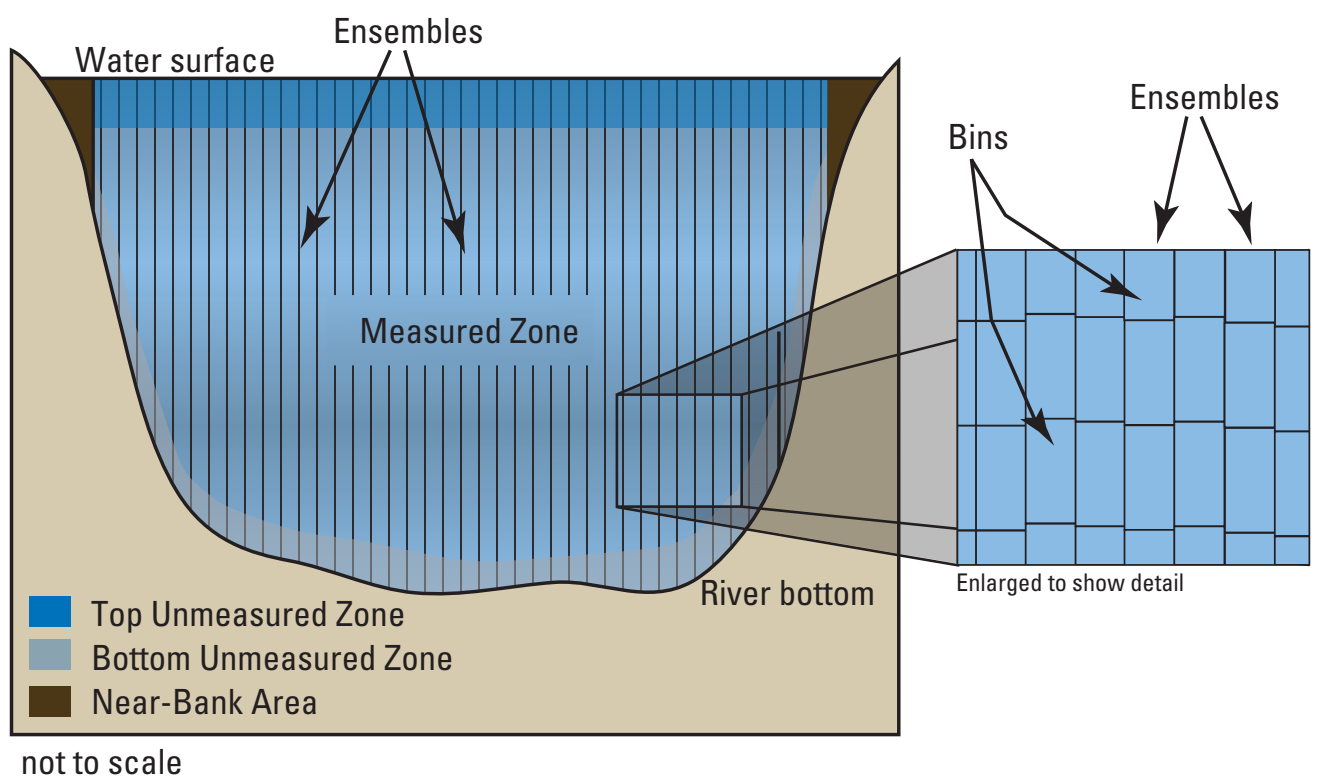

Figure 8. Schematic vertical section of river showing location of zone in which acoustic Doppler current profiler (ADCP) data were obtained for suspended-sediment concentration (SSC) computation, and zones in which ADCP data were unavailable and SSC estimated.

weighted by the respective estimated discharges ( $Q_{b o t}$ and $\left.Q_{t o p}\right)$ in each zone for each ensemble. Discharge estimates in the unmeasured near-surface zone were based on a 3-point solution when applicable; otherwise a constant-extrapolation method (RD Instruments, 2003) was used. Discharge estimates for the unmeasured near-bottom zone were based on a power curve solution (RD Instruments, 2003).

SSC values for near-bank areas where the boat could not reach shore, or where the water was too shallow for the ADCP were estimated for the left and right banks $\left(S_{S S}\right.$ and $\left.S S C_{r}\right)$; these terms represent the flow-weighted average $S S C_{b i n}$ values in the 10 ensembles closest to the left and right banks, respectively. The SSC values for each bank were weighted by corresponding estimates of discharge ( $Q_{l}$ and $Q_{r}$ ) from the same 10 ensembles for each bank in accordance with standard methods (RD Instruments, 2003).

The estimated cross-sectional average SSC values are plotted against the velocity-weighted SSC average estimated by use of the upward-looking ADCP in figure 9. If necessary, an SSC value was interpolated between upwardlooking ADCP measurements to correspond with the mean time of the cross-section measurement. A linear-regression equation relating these parameters was generated to adjust the upward-looking ADCP estimate to conditions in the full cross section. The number of cross-section measurements made in each calibration trip varied; therefore, bias toward a particular calibration trip was avoided by a random sampling of no more than 4 measurements from each trip and no fewer than 3 ( 3 measurements were made on 2 trips). The resulting equation (equation 13) represents 94 cross-section measurements made during 24 calibration trips between 2002 and 2004; it has an $\mathrm{R}^{2}$ of 0.90 and a residual standard error of $4.62 \mathrm{mg} / \mathrm{L}$ :

$$
S S C_{\text {avg }}=1.178 \times S S C_{\text {Pavg }}-1.019
$$

The percent error for each of the correction and normalization factors discussed above for these specific instruments at this site during a single 208-day deployment is summarized in table 3.
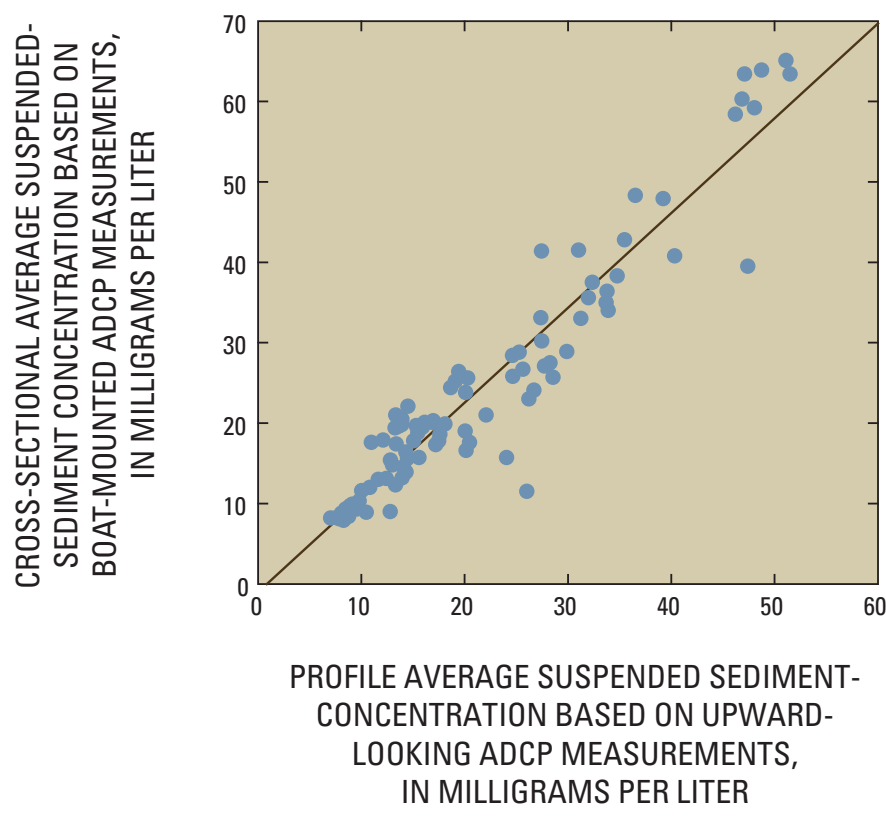

Figure 9. Relation between estimates of suspended-sediment concentration based on upward-looking acoustic Doppler current profiler (ADCP) measurements and those based on boat-mounted cross-sectional ADCP measurements. 
Table 3. Percent error resulting from omission of corrections and normalizations to data collected during a 208-day acoustic Doppler current profiler (ADCP) deployment in the Hudson River near Poughkeepsie, N.Y.

\begin{tabular}{|c|c|c|}
\hline Factor & $\begin{array}{l}\text { Observed } \\
\text { range }\end{array}$ & $\begin{array}{c}\text { Percent error } \\
\text { in calculated } \\
\text { suspended- } \\
\text { sediment discharge } \\
\text { without accounting } \\
\text { for factor }\end{array}$ \\
\hline Transmit power (p. 4) & $\begin{array}{l}71 \text { to } 65 \\
\text { watts }\end{array}$ & $36^{1}(-5.1)$ \\
\hline Transmit length (p. 4) & 45 to 47 units & $-1.0^{1}(-0.3)$ \\
\hline Beam normalization (p. 5) & See table 2 & 6.5 \\
\hline Beam spreading (p. 5) & $\begin{array}{l}\sim 0.9 \text { to } 17.4 \\
\text { m depth }\end{array}$ & -71 \\
\hline $\begin{array}{l}\text { Near-field correction (p. } \\
\text { 5) }\end{array}$ & N/A & -1 \\
\hline Sound absorption (p. 6) & $\begin{array}{l}\sim 0.9 \text { to } 17.4 \\
\text { m depth }\end{array}$ & -18 \\
\hline Bias correction (p. 8) & N/A & -3.2 \\
\hline $\begin{array}{l}\text { Cross-section correction } \\
\text { (p. 9) }\end{array}$ & N/A & -13 \\
\hline
\end{tabular}

${ }^{1}$ First number accounts for changes during deployment and differences between calibration and deployment. Numbers in parenthesis only include changes during the deployment. N/A, Not Applicable.

\section{Computation of Water Discharge}

Water discharge in this study was based on multiple regression relations between boat-mounted ADCP-measured discharge and two or three explanatory variables-(1) the stream-wise average velocity measured by the upward-looking ADCP, (2) wind stress, and (3) river stage when the ADCPderived depth-averaged velocity was less then $0.9 \mathrm{~cm} / \mathrm{second}$. The conventional "index-velocity" method of discharge calculation in tidal rivers (Rantz, 1982) produced similar estimates for the flood discharge but less satisfactory estimates of the ebb discharge relative to the multiple regression approach. The regression of measured discharge against depth-averaged down-river water velocities greater than $0.9 \mathrm{~cm} / \mathrm{second}$ and wind stress (fig. 10) yielded the following equation for calculation of ebb discharge $(Q)$, in cubic feet per second:

where

$$
Q=118548.1 \times p w s+658.5 \times W S-1729.5
$$

pws is the depth-averaged, down-river water velocity, measured by the upward-looking ADCP, in meters per second;

and $W S$ is wind stress, in newtons per square meter.
The regression of measured discharge against downriver water velocities less than or equal to $0.9 \mathrm{~cm} / \mathrm{second}$, river stage, and wind stress yielded the following equation for calculation of flood discharge (Q), in cubic feet per second:

$Q=126139.8 \times p w s-13051.3 \times R S+235.9 \times W S-511.6$

where

$R S$ is river stage, in feet.

Equation 14a is based on 44 discharge measurements made during 18 calibration trips with a boat-mounted ADCP between March 2002 and May 2005 and has an $R^{2}$ value of 0.97 . Equation $14 \mathrm{~b}$ is based on 35 discharge measurements made during 14 calibration trips with a boat-mounted ADCP between March 2002 and May 2005 and has an $\mathrm{R}^{2}$ value of 0.99 . For both equations $p w s$ was significant at the $p<0.001$ level; $W S$ was significant at the $p<0.001$ level for equation 14 a and $p=0.0012$ for equation $14 \mathrm{~b}$; river stage was significant at the $p<0.001$ level for equation $14 \mathrm{~b}$, but had a $p$ value of 0.65 for the ebb discharge and was therefore not included in equation 14a.

The boat-mounted ADCP-measured discharges were calculated with RD Instruments WinRiver software version 10.06. Discharge was measured according to established USGS protocols (U.S. Geological Survey, 2002) with two exceptions necessitated by the large width and constantly changing flow conditions in this tidal river. First, individual discharge measurements were made within about 15 minutes
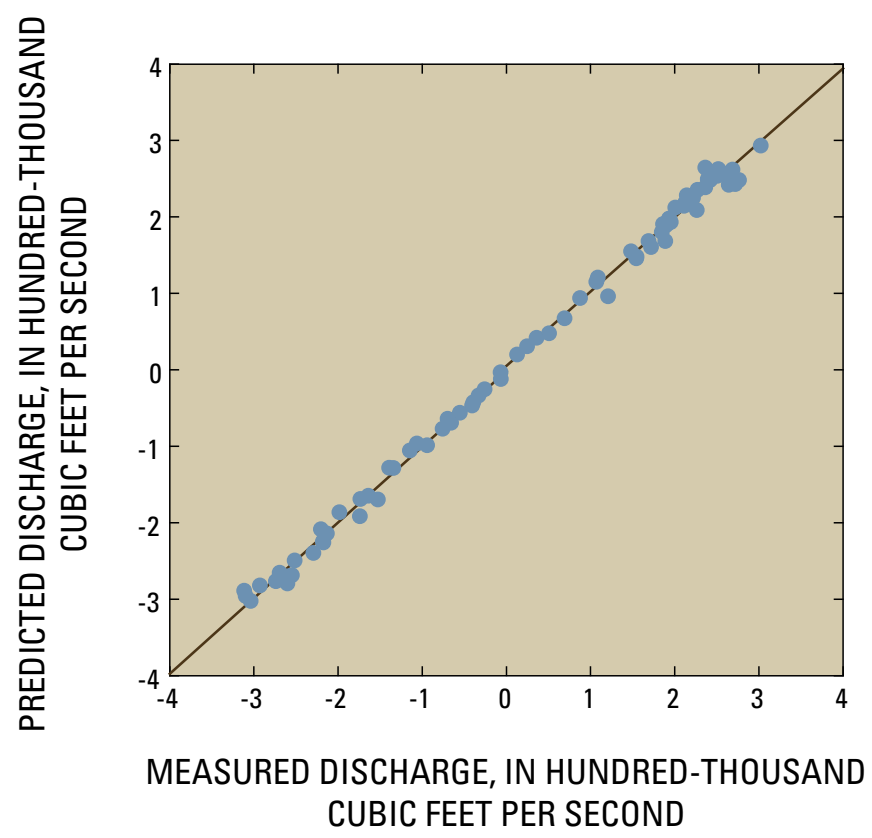

Figure 10. Relation between discharge predicted by equations $14 \mathrm{a}$ and $14 \mathrm{~b}$ and measured by boat-mounted acoustic Doppler current profiler. 
to minimize time-averaging the measurement; this almost always resulted in boat speeds (about $1 \mathrm{~m} / \mathrm{s}$ ) that exceeded the water speed (maximum about $0.7 \mathrm{~m} / \mathrm{s}$ ). Second, individual measurements were used instead of the average of four or more consecutive measurements and were deemed acceptable if consecutive measurements yielded consistently increasing or decreasing values, and if the differences between successive values seemed reasonable in terms of the tidal phase at the time of the measurement. For the development of equations $14 \mathrm{a}$ and $14 \mathrm{~b}$, the upward-looking ADCP data, atmospheric data needed for computation of wind stress, and river stage were measured at 15-minute intervals and interpolated as necessary to match the mean time of the discharge measurement.

Meteorological data needed to calculate WS and river stage were recorded at the USGS streamflow-gaging station adjacent to the river cross section. Air temperature and barometric pressure from a USGS atmospheric station in Troy, N.Y. (site 424051073414401) were used for times when these data were unavailable at the gaging station. Differences in barometric pressure between the sites were negligible after correction for elevation. Air-temperature differences at the study site averaged $1.3{ }^{\circ} \mathrm{C}$ higher than at Troy for June 2003 to July 2004, and missing data were adjusted accordingly, although such small differences have little effect on wind stress and even less on the computed discharge. Wind speed at the study site was averaged over a 5-minute period preceding each quarter-hour, and wind direction, barometric pressure, and air temperature were measured on the quarter hour. WS, in units of newtons per square meter, was computed as:

$$
W S=\frac{B p}{287 \times A t} \times C d \times|(p a s-p w s)| \times(p a s-p w s)
$$

where

$B p$ is the barometric pressure, in pascals;

At is the air temperature, in degrees Kelvin;

Cd is a dimensionless drag coefficient from

Trenberth and others (1990);

and

pas is the down-river wind speed, averaged over the previous 2 hours, in meters per second.

\section{Computation of Suspended-Sediment Discharge}

Instantaneous suspended-sediment discharge was computed by multiplying $Q$ from equation 14 a or 14 b by $S S C_{a v g}$ from equation 13, and converting units. Suspendedsediment discharge calculated for tidal settings over periods other than tidal cycles are biased with respect to one another, because the calculated difference between two periods of equal duration may be attributable to the part of the tidal cycle over which the respective periods were computed (fig. 11). Suspended-sediment discharge computation over successive tidal cycles, however, is awkward to manage in the context of a calendar day. Mathematically filtering the time-series data removes the semidiurnal tide signal from the data and the resulting bias from summing the discharge over incomplete tidal cycles. Similarly, computing long-term totals of instantaneous suspended-sediment discharge over periods much longer than a tidal cycle has the effect of minimizing this bias as indicated in fig. 11C. Therefore computations of annual suspended-sediment discharge computed either using a tidal filter or by simple summation of instantaneous data, should be nearly identical.

A low-pass digital filter was used to remove the semidiurnal tide signal from the time-series data. A copy of the VB.net code for the filter, originally written in FORTRAN by J. Wang and J. Burau of the USGS, is given in the appendix. The filter is a fast Fourier transform (FFT) set to remove fixed-frequency signals in the time-series data with a period of less than 30 hours (this also results in the removal of any diurnal signals). The FFT considers the value of data beyond the beginning and end of an individual data set as zero, which results in oscillations in the transformed data near the ends of the data set. For this reason, the first and last 100 data points (100 15-minute values) from each time-series data set were considered unusable. The filter residual represents the net, or downriver, suspended-sediment discharge. Each filtered data point was assumed to represent the instantaneous suspended-sediment discharge at any point in time over the next 15 minutes; therefore, each filtered value was multiplied by 15 to provide an estimate of the total sediment discharge over the 15 minutes that followed the measurement. Summation of the 96 15-minute suspended-sediment discharge values for each day constitutes the net daily suspendedsediment discharge. 

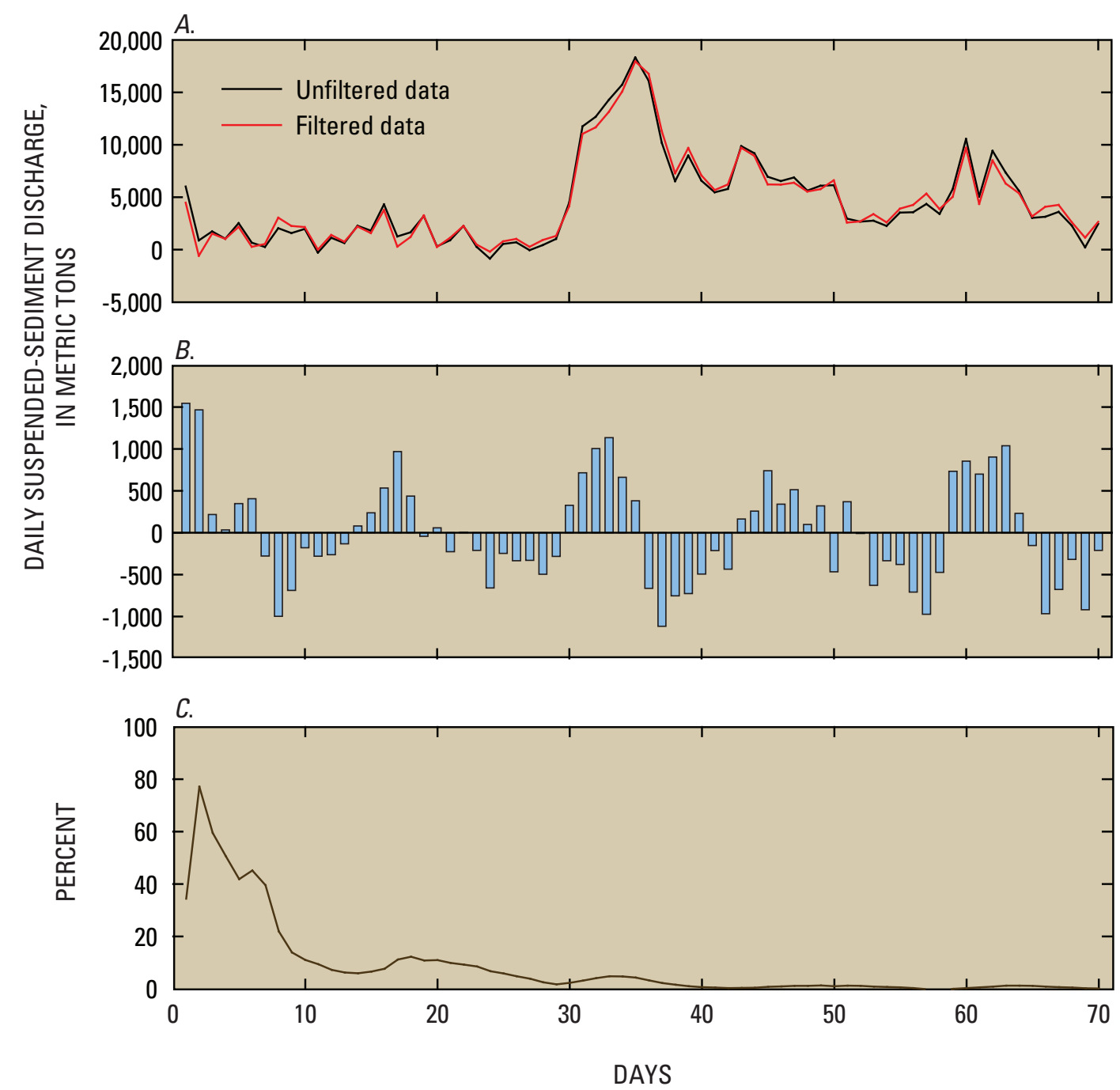

Figure 11. A. Daily suspended-sediment discharge computed with tidal-filtered and unfiltered data. $B$. Daily difference between filtered and unfiltered values computed in $A$. $C$. Percent difference between cumulative filtered and unfiltered data over time. 


\section{Summary}

In 2001, the USGS, in cooperation with the New York State Department of Environmental Conservation, designed a sampling protocol and computational procedure to process ADCP data to determine suspended-sediment discharge. Suspended-sediment discharge was computed using measures of echo intensity (EI) and velocity from an acoustic Doppler current profiler (ADCP) at the USGS study site in the freshwater-tidal Hudson River near Poughkeepsie, N.Y., for the assessment of sediment discharge toward New York Harbor. Adjustments to EI data included an instrument- and beam-specific EI conversion to decibels, normalizations for temporal and instrument variations in transmit power and length, beam-to-beam variability, and range-dependent corrections. Calibration of EI to suspended-sediment concentration (SSC) involved the collection of boat-mounted ADCP data from bins corresponding to the depth of a P-61 isokinetic water sampler lowered from the opposite side of the boat. Cross-sectional SSC estimates, based on boat-mounted ADCP measurements were used to adjust data collected by the fixed-position, upward-looking ADCP to conditions in the river cross section. Water discharge was estimated through multiple-regression relations between boat-mounted ADCPmeasured discharge and explanatory variables of wind stress, stage, and upward-looking ADCP measures of depth-averaged velocity. Net suspended-sediment discharge was computed by filtering 15-minute time-series data of instantaneous suspended-sediment discharge with a low-pass digital filter that used a fast-Fourier transform to remove the semidiurnal tidal signal in the data.

\section{Acknowledgments}

Jeff Gartner and Randal Dienhart of USGS provided comments on a draft of this report which greatly improved the final product. Rocky Geyer of Woods Hole Oceanographic Institution and John Gray of USGS have been strong advocates for this work. Special thanks to Don White and White's Marine for keeping us on the river and Fran Dunwell and the New York State Department of Environmental Conservation's Hudson River Estuary Program for investing in the equipment necessary to do this work.

\section{References Cited}

Center for Operational Oceanographic Products and Services, 2005, Tidal station locations and ranges, accessed September 15, 2005, at http://co-ops.nos.noaa.gov/tides05/ tab2ec2a.html\#23.
Deines, K.L., 1999, Backscatter estimation using broadband acoustic Doppler current profilers in Oceans 99 MTS/IEEE Conference Proceedings, September 13-16, 1999, Seattle, Wash.

deVries, M.P. and Weiss, L.A., 2001, Salt-front movement in the Hudson River Estuary, New York-Simulations by one-dimensional flow and solute-transport models: U.S. Geological Survey Water-Resources Investigations Report 99-4024, 69 p.

Downing, Andrew, Thorne, P.D., and Vincent, C.E., 1995, Backscattering from a suspension in the near-field of a piston transducer: The Journal of the Acoustical Society of America, v. 97, no. 3, p. 1614.

Flammer, G.H. 1962, Ultrasonic measurement of suspended sediment: U.S. Geological Survey Bulletin 1141-A, 48 p.

Gartner, J., 2004, Estimating suspended solids concentrations from backscatter intensity measured by acoustic Doppler current profiler in San Francisco Bay, California: Marine Geology, v. 211, p.169-187.

Gartner, J.W. and Cheng, R.T., 2001, The promises and pitfalls of estimating total suspended solids based on backscatter intensity from acoustic Doppler current profilers, in Proceedings of the Seventh Federal Interagency Sedimentation Conference, March 25-29, 2001, Reno, Nev., p. III-126.

Gartner, J.W., Mueller, D.S., Wall, G.R., and Gray, J.R., 2003, Breakout Session 4: Other fluvial-sediment surrogates, in, Gray, J. and Glysson, G.D. (eds), Proceedings of the Federal Interagency Workshop on Turbidity and Other Sediment Surrogates: April 30-May 3, 2002, Reno, Nev.: U.S. Geological Survey Circular 1250, 56 p.

Helsel, D.R., and Hirsch, R.M., 1992, Statistical methods in water resources, studies in environmental science, Elsevier Science B.V., v. 49, 529 p.

Morlock, S.E., Nguyen, H.T., and Ross, J.H., 2002, Feasibility of acoustic Doppler velocity meters for the production of discharge records from the U.S. Geological Survey streamflow-gaging stations: U.S. Geological Survey Water-Resources Investigations Report 01-4157, 56 p.

Potterfield, G., 1972, Computation of fluvial-sediment discharge: U.S. Geological Survey, Techniques of WaterResources Investigations, chap. C3, 66 p.

Press, W.H., Flannery, B.P., Teukolsky, S.A., and Vetterling, W.T., 1992, Numerical recipes in Fortran 77: The art of scientific computing: Cambridge University Press, 933 p. 
Rantz, S.E., 1982, Measurement and computation of streamflow: volume 2. computation of discharge: U.S. Geological Survey Water-Supply Paper 2175, 631 p.

RD Instruments, 1996, Principles of operation: A practical primer: $158 \mathrm{p}$.

RD Instruments, 2003, WinRiver users guide-USGS version: $144 \mathrm{p}$.

Reichel, G., and Nachtnebel, H.P., 1994. Suspended sediment monitoring in a fluvial environment: Advantages and limitations applying an acoustic Doppler current profiler: Water Research, v. 28, no. 4, p. 751-761.

Schaafsma, A.J., Lafort, A.M., Guyomar, Daniel, 1997, Development of an acoustic method and prototype instrumentation for size and concentration measurement of suspended sediment in Proceedings of the First International Conference on EuroGOOS, 7-11 October 1996, The Hague: The Netherlands (Elsevier), p. 168-175.

Shulkin, M. and Marsh, H.W., 1962, Sound absorption in sea water: The Journal of the Acoustical Society of America, v. 34 , no. 6 , p. 864 .
Simpson, M.R. and Oltman, R.N., 1993, Dischargemeasurement system using an acoustic Doppler current profiler with applications to large rivers and estuaries: U.S. Geological Survey Water-Supply Paper 2395, 32 p.

Trenberth, K.E., Large, W.G. and Olson, J.G., 1990, The mean annual cycle in global ocean wind stress: Journal of Oceanography, v. 20, p. 1742.

Urick, R.J., 1948, The absorption of sound in suspensions of irregular particles: The Journal of the Acoustical Society of America, v. 20, no. 1, p. 283-289.

U.S. Geological Survey, 1999, National field manual for the collection of water quality data: Techniques of WaterResources Investigations, Book 9, chap. A4, 103 p.

U.S. Geological Survey, 2002, Policy and technical guidance on discharge measurements using acoustic Doppler current profilers: U.S. Geological Survey Office of Surface Water Technical Memo 2002.02.

Wang, Jias and Cheng, R.T., 1993, On low-pass digital filters in oceanography: Acta Oceanologica Sinica, v. 12, no. 2, p. 183-196. 


\section{Appendix}

Below is the VB.net code used to low-pass filter the semidiurnal tide signal from a time series of instantaneous suspended-sediment discharge data. Subroutines realft and four1 are from Press and others (1992). Subroutines dfilt and setup are modified from J. Wang and J. Burau (U.S. Geological Survey, written commun., 1994) and based on Wang and Chen, (1993). The following variable definitions were used in data processing; all other variables are used for data manipulation.

loadinst(i) contains the suspended-sediment discharge data to be filtered

Load15(q) contains the filtered suspended-sediment discharge data

ntap $=100$ (number of points to taper)

ntaper $=1$ (cosine taper indicator)

$\mathrm{dt}=15$ (data interval in minutes)

tlps $=40$ (low-pass pass period in hours)

tlstp $=30$ (low-pass stop period in hours)



\section{End If}

Next i

End Sub

Sub dfilt()
Dim jb As Integer

ntotal $=0$

While ntotal $<\operatorname{maxd}$

$\mathrm{jb}=\mathrm{jb}+1$

ntotal $=2^{\wedge} \mathrm{jb}$

End While

$\mathrm{dt} 6=\mathrm{dt} / 60$

$\mathrm{df}=1 /($ ntotal $* \mathrm{dt} 6)$

flps $=1 /$ tlps

flstp $=1 /$ tlstp

nlps $=2 * \operatorname{Fix}(\mathrm{flps} / \mathrm{df})+1$

nlstp $=2 * \operatorname{Fix}($ flstp $/$ df $)+1$

$\mathrm{dnl}=$ nlstp - nlps

For $\mathrm{q}=1$ To 131072

$\operatorname{Data}(q)=0$

$\operatorname{xmask}(\mathrm{q})=1$

Next q

For $\mathrm{q}=1$ To ntotal

$\operatorname{Data}(q)=\operatorname{dch}(q)$

Next q

If ntaper $<>0$ Then

For $\mathrm{v}=1$ To ntap

$\operatorname{argh}=$ Math.PI * (v - 1) / (ntap)

$\mathrm{ah}=0.5-0.5 *$ Math.Cos(argh)

$\operatorname{Data}(\mathrm{v})=\mathrm{ah} * \operatorname{Data}(\mathrm{v})$

$\operatorname{Data}(\operatorname{maxd}+1-\mathrm{v})=$ ah $* \operatorname{Data}(\operatorname{maxd}+1-\mathrm{v})$

Next

End If

$\mathrm{nn}=2 *$ ntotal

$\mathrm{n} 2=\mathrm{ntotal} / 2$

realft(n2, 1)

ntt $=$ ntotal

For $\mathrm{v}=$ nlps To $n t t$

$\arg =(\mathrm{nlstp}-\mathrm{v}) / \mathrm{dnl}$

If $\mathrm{v}<$ nlstp Then $\mathrm{a}=0.5-0.5 *$ Math.Cos(Math.PI $* \arg$ )

If $\mathrm{v}>=$ nlstp Then $\mathrm{a}=0$

$\operatorname{Data}(\mathrm{v})=\mathrm{a} * \operatorname{Data}(\mathrm{v})$

$\operatorname{xmask}(\mathrm{v})=\mathrm{a}$

Next $\mathrm{v}$

realft(n2,-1)

$\mathrm{a}=2 /$ ntotal

For $\mathrm{k}=1$ To ntotal

$\operatorname{Data}(\mathrm{k})=\mathrm{a} * \operatorname{Data}(\mathrm{k})$

Next k

npts $=$ maxd - ntap

End Sub

Sub realft(ByVal n2, ByVal isign)

Dim wr, wi, wpr, wpi, wtemp, theta As Double

theta $=6.28318530717959 / 2 / \mathrm{n} 2$

$\mathrm{c} 1=0.5$

If isign $=1$ Then 

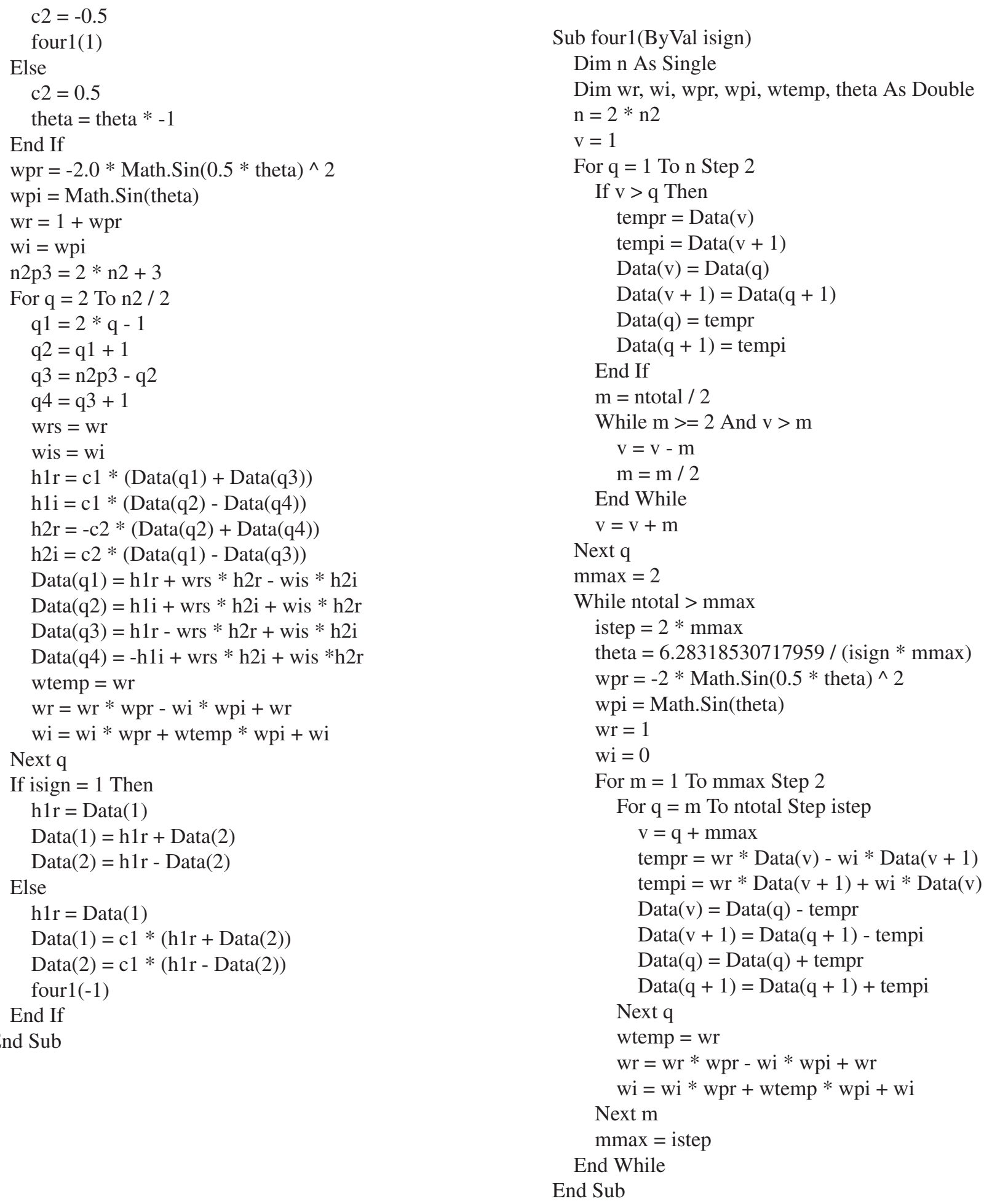
For additional information write to:

New York Water Science Center

U.S. Geological Survey

425 Jordan Road.

Troy, N.Y. 12180

Information requests:

(518) 285-5602

or visit our web site at;

http://ny.water.usgs.gov 

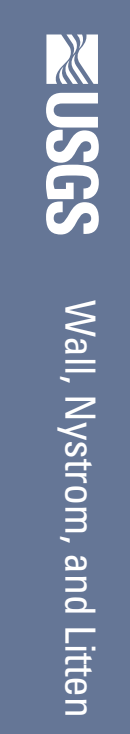

두으.

옥음

을

둥

बे

긍응

프를

등

을

홍

쪼욤

옥 응

$\sum_{i}^{\mathbb{D}} \frac{0}{\dot{d}}$

文焉

읏 홀

$\frac{\sim}{D J}$

용

감 